\title{
PALMITOLEIC ACID HAS STRONGER ANTI-INFLAMMATORY POTENTIAL IN HUMAN ENDOTHELIAL CELLS COMPARED TO OLEIC AND PALMITIC ACIDS
}

Running title: Palmitic, oleic and palmitoleic acids and endothelial cells

Camila O Souza ${ }^{1 *}$, Carina A. Valenzuela ${ }^{2,3 *}$, Ella J Baker ${ }^{2}$, Elizabeth A Miles ${ }^{2}$, José C Rosa Neto ${ }^{1}$, Philip C Calder ${ }^{2,4}$

*authors contributed equally to this work.

${ }^{1}$ Department of Cell and Developmental Biology, University of São Paulo, São Paulo, Brazil.

${ }^{2}$ Human Development and Health Academic Unit, Faculty of Medicine, University of Southampton, Southampton, United Kingdom.

${ }^{3}$ School of Nutrition, Faculty of Pharmacy, University of Valparaíso, Valparaíso, Chile

${ }^{4}$ NIHR Southampton Biomedical Research Centre, University Hospital Southampton NHS Foundation Trust and University of Southampton, Southampton, United Kingdom

\section{Corresponding author:}

Camila O Souza ${ }^{1,2}$

souza.co@usp.br

camila.oliveiradesouza@UTsouthwestern.edu

${ }^{1}$ Department of Cell and Developmental Biology, University of São Paulo, São Paulo, SP, Brazil.

2 Touchstone Diabetes Center, Department of Internal Medicine, University of Texas Southwestern, Dallas, TX, USA. 


\section{ABSTRACT}

Fatty acids (FAs) may affect endothelial cell (EC) function, influencing atherogenesis and inflammatory processes. Palmitoleic acid (POA) has been described as an antiinflammatory FA. However, its effects on ECs are underexplored. This study compared the effects of POA with those of palmitic acid (PA) and oleic acid (OA) on EC inflammatory responses. EAHy926 cells (EC lineage) were exposed to PA, OA or POA, and then stimulated with tumour necrosis factor (TNF)- $\alpha$. Associated with the cellular incorporation of the FA added to the medium, PA induced a 2-fold increase in arachidonic acid, while POA increased the amount of cis-vaccenic acid. PA, but not OA, enhanced the production of IL-6 and IL-8 in response to TNFa. In contrast, POA decreased production of MCP-1, IL-6 and IL-8 when compared to PA. TNF $\alpha$ increased surface ICAM-1 expression which was decreased by POA. TNFa stimulation increased the expression of NFKB, COX-2, MCP-1 and IL-6 genes and reduced the expression of PPAR $\alpha$ gene. PA enhanced the expression of MCP-1, IL-6 and COX-2 genes, while POA downregulated these genes, decreased expression of NFkB gene and upregulated PPARa gene expression. In conclusion, POA has anti-inflammatory effects on ECs stimulated with TNFa and may counter endothelial dysfunction.

Keywords: Palmitoleic acid; EAHy926 cells; TNFa; Endothelial dysfunction; Cytokines; Inflammation. 


\section{INTRODUCTION}

Atherosclerosis is often described as an inflammatory disease ${ }^{[1]}$. Elevated levels of free fatty acids, frequently observed in hyperlipidemic, hypertensive and atherosclerotic patients, are a common feature of patients with metabolic syndrome and visceral obesity ${ }^{[2,3}$. Atherosclerosis is initiated by endothelial dysfunction, triggered by pathological stresses such as hyperlipidemia and hypertension. The "activated" endothelial cells synthesize cell surface adhesion molecules such as selectins and integrins, which promote attachment of immune cells such as monocytes to the endothelium and subsequently their migration into the vascular wall ${ }^{[1]}$. The nuclear transcription factor-kappa $B(N F \kappa B)$ is a prototypical activator of gene expression in response to oxidative stress and inflammatory triggers, leading to endothelial dysfunction and upregulation of pro-inflammatory mediators ${ }^{[4,5]}$. Amongst the latter are chemokines (MCP-1, monocyte chemotactic protein; RANTES, regulated on activation normal T cell expressed and secreted), cell adhesion molecules (ICAM-1, intercellular adhesion molecule-1), cytokines (IL-6, interleukin-6; IL-8, interleukin-8; TNFa, tumor necrosis factor), growth factors (VEGF, vascular endothelial growth factor) and prothrombotic substances ${ }^{[6]}$. These result in increased migration of monocytes into the vascular wall, where they begin the phagocytosis of lipid particles (e.g. oxidized low density lipoprotein), evolve into macrophages and finally into foam cells ${ }^{[1]}$. Foam cells produce chemokines to attract additional monocytes leading to formation of the atherosclerotic plaque ${ }^{[7]}$.

Saturated fatty acids (SFAs) have effects linked to the initiation and progression of atherosclerosis ${ }^{[8]}$ including effects on endothelial cells (ECs) ${ }^{[2,8]}$. For example, palmitate (PA, $\mathrm{C} 16: 0)$ and stearate (C18:0), by triggering the proinflammatory transcription factor $N F K B$ in ECs, promote the initial steps of atherogenesis [6, 9]. These SFAs enhance the adherence and transmigration of monocytes and lymphocytes by increasing the expression of cell adhesion molecules (ICAM-1, VCAM-1 and E-selectin), up-regulate the production of inflammatory cytokines (TNFa, IL-6 and IL-8) and promote apoptosis ${ }^{[6,9,10]}$. On the other hand, the effects of the monounsaturated fatty acid oleic acid (OA, C18:1n-9) on ECs are less clear. Some authors observed that OA reduced the expression of VCAM-1 and ICAM-1 on human umbilical vein ECs (HUVECs), as well as the levels of the pro-inflammatory cytokines TNFa, IL-6 and MCP-1 ${ }^{[6,9,10]}$, protecting the cells from the pro-apoptotic and inflammatory effects of palmitate and stearate ${ }^{[3]}$. However, higher levels of OA (400 $\mu \mathrm{M}$ ) were found to lead to production of mitochondrial-derived reactive oxygen species and hence endothelial dysfunction ${ }^{[11]}$. 
The effects of palmitoleic acid (POA, C16:1n-7), another monounsaturated fatty acid, which can be obtained from macadamia (Macadamia integrifolia) nuts, macadamia oil, and sea buckthorn (Hippophae rhamnoides) oil ${ }^{[12]}$, are largely unknown and underexplored, especially with regard to ECs. In other cell types, POA seems to promote anti-inflammatory effects ${ }^{[12]}$, and even reduces the harmful effects of saturated fatty acids ${ }^{[3,13]}$. For example, POA promoted the differentiation of primary macrophages into the anti-inflammatory M2 phenotype, protecting against the proinflammatory effects of PA ${ }^{[13]}$. POA also lowered the levels of pro-inflammatory cytokines produced by LPS stimulated macrophages ${ }^{[14]}$. Similarly, POA reduced the pro-apoptotic effects of PA and stearic acid on ECs ${ }^{[3]}$.

Thus, we hypothesized that POA would promote beneficial anti-inflammatory effects in ECs. To test this, we compared the effects of POA with those of PA and OA using the HUVEC derived EAHy926 cell line.

\section{METHODS}

\subsection{Endothelial cell culture}

EAHy926 cells (ATCC®; LGC Standards, Middlesex, UK) were cultured in high glucose containing DMEM supplemented with $10 \%$ fetal bovine serum, $1 \%$ Lglutamine-penicillin-streptomycin solution and 1\% HAT supplement $(100 \mu \mathrm{M}$ hypoxanthine, $0.4 \mu \mathrm{M}$ aminopterin and $16 \mu \mathrm{M}$ thymidine); medium and medium supplements were all from Sigma-Aldrich, Gillingham, UK. Cultures were maintained at $37^{\circ} \mathrm{C}$ in a humidified $95 \%$ air $/ 5 \% \mathrm{CO}_{2}$ incubator. For the experiments, $32,000 \mathrm{cells} / \mathrm{cm}^{2}$ were seeded in 96 well plates (MTT and ELISA), 6 well plates (flow cytometry and Real Time PCR) or T25 flasks (gas chromatography), cultured in complete medium and exposed to PA, OA or POA (20 or $50 \mu \mathrm{M}$ ) for 48 hours, followed by incubation with or without TNFa $(1 \mathrm{ng} / \mathrm{mL})$ for 6 or 24 hours.

\subsection{Fatty acid treatment}

PA, OA and POA (all from Sigma-Aldrich, Gillingham, UK) were prepared as 20 $\mathrm{mM}$ and $50 \mathrm{mM}$ stock solutions in $100 \%$ ethanol. Before each experiment the stock solutions were diluted in complete culture medium to yield final FA concentrations of 20 and $50 \mu \mathrm{M}$. The corresponding control was a $0.1 \%$ ethanol solution diluted in complete medium. 


\subsection{Cell viability assay (MTT assay)}

For the assessment of cell viability, EAHy926 cells were incubated (96 well plate, 32,000 cells $/ \mathrm{cm}^{2}$ ) with different concentrations of PA, OA or POA (1 to $500 \mathrm{uM}$ ) for 48 hours and exposed to complete medium with or without TNFa (1 ng/mL) for 24 hours. After this, the cell medium was replaced by DMEM containing $0.05 \mathrm{mg} / \mathrm{mL}$ of MTT (3-(4,5-dimethylthiazol-2-yl)-2,5-diphenyltetrazolium bromide; Sigma-Aldrich, Gillingham, UK) (100 $\mu \mathrm{L}$ per well) and the cells were cultured for another 4 hours. The supernatant was removed $(75 \mu \mathrm{l})$ and replaced by DMSO. Absorbance was measured at $550 \mathrm{~nm}$ on a plate reader. The effect of the FAs and TNFa on cell viability was normalized to the control cultures set at $100 \%$.

\subsection{Gas chromatography}

The incorporation of the FAs into cultured EAHy926 cells was confirmed through FA analysis of the cells using gas chromatography. EAHy926 cells were submitted to lipid extraction with chloroform/methanol as described elsewhere ${ }^{[15]}$. The lipid extracts were dried under nitrogen. Neutral and polar lipids were separated from these extracts using solid phase extraction chromatography ${ }^{[15]}$. FA from within the polar (phospholipids) and neutral (triglycerides) lipid fractions were methylated to form methyl esters, by heating with methanol in sulphuric acid. The FA methyl esters were separated and analyzed by gas chromatography using conditions described elsewhere ${ }^{[15]}$. FA are expressed as ug $/ 10^{6}$ cells.

\subsection{Multiplex Magnetic Enzyme-Linked Immunosorbent Assay (ELISA)}

Cell culture supernatants were assayed by Human Magnetic Luminex Screening Assay ELISA (R\&D Systems, Minneapolis, MN, USA) for the appearance of inflammatory factors MCP-1 (1 to $8036 \mathrm{pg} / \mathrm{mL}$ ), IL-6 (4.6 to $3433 \mathrm{pg} / \mathrm{mL}$ ), IL-8 (2.6 to $2012 \mathrm{pg} / \mathrm{mL}$ ), VEGF (4.3 to $3219 \mathrm{pg} / \mathrm{mL}$ ), RANTES (7.2 to $5251 \mathrm{pg} / \mathrm{mL}$ ) and ICAM-1 (2323.5 to $1794000 \mathrm{pg} / \mathrm{mL}$ ). Assays were conducted according to the manufacturer's instructions. Plates were read on a Bio-plex 200 System.

\subsection{Flow cytometry}

The appearance of the adhesion molecule ICAM-1 (CD54) on the surface of EAHy926 cells was determined by flow cytometry. Following treatment, the cells were detached, centrifuged and stained with phycoerythrin (PE) conjugated monoclonal human antibody to CD54 (BD Biosciences ${ }^{\circledR}$, San Jose, CA, USA) diluted in a staining solution (PBS, 2\% BSA) for $30 \mathrm{~min}$. Mouse lgG1 (PE) isotype was used as negative control. After staining, the cells were analyzed by flow cytometry in a FACSCalibur (BD 
Biosciences ${ }^{\circledR}$ ). Both $\%$ of gated cells and median fluorescent intensity (MFI) were determined.

2.7. RNA isolation, Reverse Transcription, and Real-Time PCR.

Changes in inflammatory gene expression were analyzed by RT-PCR. The expression of NFKB (Hs00765730_m1), IL-6 (Hs00985639_m1), PPARa (Hs00947536_m1), MCP-1 (Hs00234140_m1) and COX-2 (Hs00153133_m1) were assessed by qRT-PCR with TaqMan ${ }^{\circledR}$ Gene Expression primers (Thermo Fisher Scientific, UK). For this, firstly the total RNA was extracted with ReliaPrep ${ }^{T M}$ RNA Cell Miniprep System (Promega, Southampton, UK) and RNA extraction kit. cDNA was synthesized from the total RNA using GoScript ${ }^{\mathrm{TM}}$ Reverse Transcriptase (Promega, UK). Quantification of gene expression was carried out using B2M (Hs00187842_m1) and $\beta$-actin (Hs01060665_g1) as internal control ("housekeeping") genes.

\subsection{Data analysis}

The data are presented as mean \pm SEM (standard error of the mean) and were analyzed by two-way analysis of variance (two-way ANOVA) followed by post-hoc tests of pairwise differences. Analyses were performed using GraphPad Prism 6.0. Differences were considered significant when $p<0.05$.

\section{RESULTS}

\subsection{FA toxicity towards EAHy926 cells}

Using an MTT-based cell viability assay it was observed that TNFa $(1 \mathrm{ng} / \mathrm{mL})$ for $24 \mathrm{~h}$ did not reduce viability of EAHy926 cells. However, $500 \mu \mathrm{M}$ of OA markedly decreased $(p<0.001)$ cell viability (Figure 1B), while concentrations of PA higher than $100 \mu \mathrm{M}$ (Figure 1A) and POA above $200 \mu \mathrm{M}$ (Figure 1C) reduced $(p<0.001)$ cell viability by $20 \%$ or more. Thus, we chose to work with FA at concentrations of $50 \mu \mathrm{M}$ and $20 \mu \mathrm{M}$ in further experiments because these concentrations did not affect cell viability (Figure 1).

\subsection{FA incorporation into EAHy926 cells}

The incorporation of FAs into EAHy926 cells was determined by gas chromatography. Incubation with PA (Figure 2A), OA (Figure 2B) or POA (Figure 2C) significantly increased $(p<0.05)$ their own incorporation in a dose response manner, with higher incorporation at 50 than $20 \mu \mathrm{M}$. TNFa did not affect the incorporation of FAs. 
Besides increasing their own concentrations in EAHy926 cells, $50 \mu \mathrm{M}$ PA and POA also induced other changes in the FA profile of the cells (Table 1). PA increased $(p<0.05)$ the concentration of SFAs, mainly its elongation product, stearic acid $(C 18: 0)$, and the PUFAs, arachidonic acid (C20:4n-6), EPA (C22:5n-3) and DHA (C22:6n-3), but with no overall change in the $n-3 / n-6$ FA ratio. POA also increased $(p<0.05)$ the concentration of its elongation product, cis-vaccenic acid (C18:1n-7). Both, OA and POA increased $(p<0.05)$ the levels of total MUFAs in EAHy926 cells.

\subsection{FA effects on the production of inflammatory factors}

6 hours of exposure to TNFa $(1 \mathrm{ng} / \mathrm{ml})$ increased $(p<0.0001)$ the production of MCP-1, IL-6 and IL-8 (Figure 3). However, besides enhancing the production of MCP-1 $(p<0.001)$, IL-6 $(p<0.01)$ and IL-8 $(p<0.0001)$ TNFa exposure for 24 hours also increased production of RANTES $(p<0.0001)$, VEGF $(p<0.01)$ and ICAM-1 $(p<0.01)$ (Figure 4).

Cells pre-incubated with $50 \mu$ M PA showed higher production of IL-6 $(p<0.001$, Figure 4B) and IL-8 ( $p<0.05$, Figure 4C) with TNFa stimulation for 24 hours, but not for 6 hours (Figure $3 B$ and $3 C$ ).

In contrast, cells pre-incubated with $50 \mu \mathrm{M}$ of POA and then stimulated with TNFa for 6 hours, showed reduced $(p<0.05)$ IL- 6 production when compared to cells pre-incubated with PA or OA (Figure 3B). After 6 hours of TNFa stimulation cells preincubated with $20 \mu \mathrm{M}$ POA also had lower production of IL-8 ( $<<0.05$, Figure $3 C$ ), while the production MCP-1 was reduced by POA at both 20 and $50 \mu \mathrm{M}(\mathrm{p}<0.05$, Figure $3 A)$. VEGF (Figure 3D), RANTES (Figure 3E) and secreted ICAM-1 (Figure 3F) were not modulated by pre-incubation with the different FAs and then stimulation with TNFa for 6 hours.

After 24 hours with TNFa, the pre-incubation with $50 \mu \mathrm{M}$ POA lowered the production of MCP-1 $(p<0.05$, Figure 4A), IL-6 ( $p<0.01$, Figure 4B) and IL-8 $(p<0.05$, Figure $4 C)$ and $20 \mu \mathrm{M}$ POA reduced the production of VEGF $(p<0.05$, Figure 4D). All three FAs at both concentrations reduced the production of RANTES, which was significantly lower $(p<0.05)$ in those cells exposed to PA or POA (Figure 4E). After 24 hours of TNFa, the levels of ICAM-1 were not affected by the incubation with the different FAs (Figure 4F).

\subsection{FA effects on cell surface ICAM-1}

Although the production of soluble ICAM-1, analyzed by Multiplex ELISA, was not modulated by TNFa or the FAs (Figure 3 and 4), the number of cells expressing ICAM-1 on their surface and the level of surface expression, observed by flow 
cytometry, were both significantly enhanced by TNFa for 6 hours $(p<0.0001$, Figure 5B, $5 \mathrm{C}, 5 \mathrm{D}$, and $5 \mathrm{E})$. Both concentrations $(20$ and $50 \mu \mathrm{M})$ of POA $(p<0.0001)$ and to a lesser extent, PA $(p<0.05)$, decreased the level of expression (MFI) of ICAM-1 on cells stimulated with TNFa, when compared to control. ICAM-1 MFI was also lower on cells pre-incubated with $50 \mu \mathrm{M}$ POA when compared to OA at same concentration $(p<0.05$, Figure $5 \mathrm{D}$ and $5 \mathrm{E})$.

\subsection{FA effects on expression of inflammation-related genes}

Finally we evaluated the effects of the FAs on inflammatory gene expression in response to TNFa (Figure 6). The expression of NFאB $(p<0.0001$, Figure $6 A), C O X-2$ $(p<0.05$, Figure 6B), MCP-1 ( $p=0.06$, Figure $6 C)$ and IL-6 $(p<0.01$, Figure $6 D)$ was upregulated by TNFa, whereas PPARa (Figure 7A, $p<0.0001$ and $7 B, p<0.05$ ) was downregulated.

Similar to the effect observed in the ELISA assay, pre-incubation with $50 \mu \mathrm{M}$ PA promoted a 2-fold induction $(\mathrm{p}<0.0001)$ in IL-6 mRNA expression. PA also enhanced the TNF $\alpha$ effects on the expression of MCP-1 $(p<0.0001)$ and COX-2 $(p<0.01)$. OA preincubation reduced $(p<0.0001)$ the expression of MCP-1 and IL-6 compared to PA. Finally, POA downregulated NFאB gene expression $(p<0.01)$, as well as the expression of MCP-1 $(p<0.0001)$ and COX-2 $(p<0.05)$, compared to PA, and of IL-6, compared to control $(p<0.05)$ and PA $(p<0.0001)$. None of the three FAs tested changed PPAR $\alpha$ gene expression, which was modulated by TNFa, after 6 hours (Figure 7A). However, after 24 hours with TNF $\alpha$, POA pre-incubation increased the expression of PPAR $\alpha$ $(p<0.05$, Figure 7B).

\section{DISCUSSION}

In this study we observed that POA has anti-inflammatory effects in EAHy926 cells compared to PA and OA. In fact, while pre-incubation with PA increased the production of several cytokines in response to TNF $\alpha$, and OA seemed to have little effect, POA decreased production of cytokines and an adhesion molecule and down regulated expression of several pro-inflammatory genes (NFKB, MCP-1, IL-6 and COX2) while at same time up regulating expression of the anti-inflammatory PPARa gene.

Interestingly incubation with PA increased the concentration of the proinflammatory FA and prostaglandin precursor, arachidonic acid (20:4n-6), while POA increased the concentration of cis vaccenic acid $(C 18: 1 n-7)$, which is suggested to be 
anti-inflammatory ${ }^{[16]}$ and also reported as a protective factor to cardiovascular diseases ${ }^{[12,17]}$.

Arachidonic acid is the most abundant polyunsaturated fatty acid in most membrane phospholipids, and is typically linked with inflammation ${ }^{[18]}$. Arachidonic acid can be mobilized by various phospholipase enzymes, most notably phospholipase A2, and subsequently be a substrate for synthesis of eicosanoids (prostaglandins, thromboxanes and leukotrienes), by action of cyclooxygenase (COX-1 and COX-2) and lipoxygenase enzymes ${ }^{[19]}$. Thus, the higher levels of arachidonic acid observed in EAHy926 cells treated with PA suggest an inflammatory effect of this SFA, which was confirmed when we observed that the pre-incubation with PA enhanced the production IL-6, IL-8, and the expression of MCP-1, IL-6 and COX-2 genes, after TNFa stimulation.

IL-6 is a multifunctional cytokine that regulates the immune response, the acute phase response and inflammation ${ }^{[5]}$, IL-8 plays an important role in the migration of leukocytes into the sub-endothelial compartment of the vascular wall in the early stages of atherosclerosis ${ }^{[20]}$, and MCP-1, a chemokine synthesized by ECs, is one of the early indicators of endothelial dysfunction responsible for the migration of monocytes and other leukocytes into the sub endothelial space ${ }^{[20]}$, besides being detected in high levels in human atherosclerotic lesions ${ }^{[21]}$ and in dysfunctional ECs ${ }^{[22]}$. Thus, the upregulation of these proteins by PA clearly demonstrates a pro-inflammatory function of this SFA and suggests a role in increasing atherosclerosis.

Regarding the elongation of POA to cis-vaccenic acid observed in the EAHy926 cells, it is important to mention that studies also indicate cis-vaccenic acid as an antiinflammatory FA. Cis-vaccenic acid has been correlated with high levels of the antiinflammatory peptide adiponectin in healthy patients ${ }^{[23]}$, reduced the production of cytokines by T-cells stimulated with TNFa ${ }^{[24]}$ and lowered liver inflammation in obese atherosclerotic rats ${ }^{[25]}$. Thus, some of the anti-inflammatory effects of POA observed in the current study, might be related to the higher levels of cis-vaccenic acid produced by the ECs pre-incubated with POA.

We observed that POA pre-incubation reduced the production of IL-6, IL-8 and MCP-1 stimulated by TNFa. In agreement with our results, other authors showed a modulation of those cytokines by POA incubation with cultured macrophages ${ }^{[13,14]}$, while providing POA or POA-enriched oils to obese mice reduced inflammation in adipose tissue ${ }^{[26]}$ and liver ${ }^{[27]}$.

Besides the beneficial effects of POA on the production of cytokines and chemokines, POA also reduced the levels of a growth factor, VEGF, which is related to endothelial dysfunction and atherogenesis. VEGF was initially described as a growth 
factor that stimulates endothelial proliferation and nitric oxide release in vitro ${ }^{\text {[28]; }}$ however, VEGF is now known as vascular permeability factor ${ }^{[29]}$, that also induces the migration of monocytes ${ }^{[30]}$. Several studies have demonstrated that inhibition of VEGF by monoclonal antibodies, glucocorticoids, leukotriene modifiers, COX-2 inhibitors and non-steroidal anti-inflammatory drugs, might contribute to a successful therapeutic approach to the treatment of inflammatory diseases ${ }^{[1,20,31]}$. In the current study, the lowest concentration of POA $(20 \mu \mathrm{M})$ reduced the production of VEGF in EAHy926 cells exposed to TNFa.

ICAM-1 is expressed on the surface of ECs where it plays a role in monocyte adhesion, thus promoting atherogenesis. ICAM-1 can also be released by ECs and circulates in the bloodstream in a soluble form ${ }^{[32]}$. We assessed both cell surface and secreted ICAM-1. Both were increased by incubation of ECs with TNF $\alpha$. Firstly, we observed that TNFa increased by 10-fold the MFI of ICAM-1 on the EAHy926 cell surface; however, other adhesion molecules, such as VCAM-1 and E-selectin were not modulated by TNF $\alpha$ (data not shown). On other hand, POA decreased the cell surface MFI of ICAM-1 compared to control and OA pre-incubated cells. Similarly, other antiinflammatory FAs, such as n-3 PUFAs and butyric acid, produced effects similar to POA, lowering the levels of ICAM-1 on the surface of HUVECs stimulated by cytokines [33]. These beneficial properties of POA might act to delay atherosclerosis.

In addition to its well known pro-oxidative role ${ }^{[34]}$, PPARa has been described as a NFKB inhibitor, capable of decreasing the production of cytokines and controlling inflammatory processes ${ }^{[35]}$. Several PPARa activators were shown to decrease endothelial dysfunction and atherogenesis ${ }^{[36]}$. Thus, the observed upregulation of PPARa (24 hours) induced by POA could be partially responsible for the antiinflammatory effect of this FA in TNFa stimulated ECs. In accordance with this observation, POA has been described as a PPAR activator ${ }^{[14,37]}$, and several of this FA's beneficial metabolic effects, such as increased activity of adipose tissue lipase and improved glucose uptake in liver, have been attributed to PPAR a activation ${ }^{[37]}$.

The main transcription factor that induces the expression of genes encoding adhesion molecules, COX-2 and pro-inflammatory cytokines (TNFa, IL-6, MCP-1 and

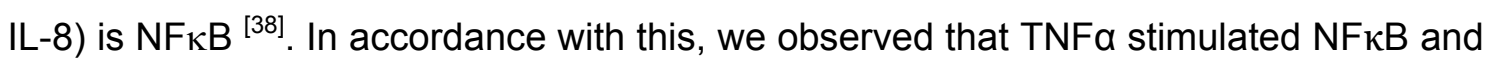
COX-2 gene expression, as well as upregulating the expression of the genes encoding the cytokines MCP-1 and IL-6. Interestingly, although PA did not modulate NFKB expression significantly, pre-incubation with this FA increased even more the expression of COX-2, MCP-1 and IL-6 genes in response to TNF $\alpha$, consistent with the endothelial dysfunction previously described ${ }^{[3]}$. 
POA showed another important anti-inflammatory role besides the reduced production of cytokines and decreased surface expression of ICAM-1, downregulating NFKB and other inflammatory genes (COX-2, MCP-1 and IL-6) stimulated by TNFa. Consistent with these observations, POA was associated with better endothelial function in healthy subjects ${ }^{[39]}$, and in patients with high cardiometabolic risk ${ }^{[40]}$, and POA treatment decreased foam cell plaques and necrotic areas in the aorta of mice fed on a hypercholesterolemic pro-atherogenic diet ${ }^{[41]}$.

\section{CONCLUSIONS}

In summary, the findings of the current study indicate that POA has antiinflammatory effects in EAHy926 cells compared to the other FAs studied. These effects seem to be mediated, at least in part, by the inhibition of NFKB gene expression and upregulation of PPARa. However, the mechanisms involved need further research to elucidate the full potential of POA as a new approach in atherosclerosis prevention and treatment.

\section{CONFLICT OF INTEREST}

The authors declare that there are no conflicts of interest.

\section{ACKNOWLEDGMENTS}

This research was supported in part by São Paulo Research FoundationFAPESP (grant 2013/04765-1; grant 2015/06376-8; grant 2016/01409-8)

\section{REFERENCES}

[1] L. G. Melo, M. Gnecchi, A. S. Pachori, D. Kong, K. Wang, X. Liu, R. E. Pratt, V. J. Dzau, Arterioscler Thromb Vasc Biol. 2004, 24, 1761.

[2] J. F. Oram, K. E. Bornfeldt, Front Biosci. 2004, 9, 1240.

[3] K. Staiger, H. Staiger, C. Weigert, C. Haas, H. U. Haring, M. Kellerer, Diabetes. 2006, 55, 3121.

[4] A. Ghosh, L. Gao, A. Thakur, P. M. Siu, C. W. K. Lai, J Biomed Sci. 2017, 24, 50. doi: $10.1186 / \mathrm{s} 12929$.

[5] C. Espinola-Klein, T. Gori, S. Blankenberg, T. Munzel, Front Biosci (Landmark Ed). 2011, 16, 1663.

[6] M. Artwohl, M. Roden, W. Waldhausl, A. Freudenthaler, S. M. BaumgartnerParzer, Faseb J. 2004, 18, 146.

[7] A. C. Li, C. J. Binder, A. Gutierrez, K. K. Brown, C. R. Plotkin, J. W. Pattison, A. F. Valledor, R. A. Davis, T. M. Willson, J. L. Witztum, W. Palinski, C. K. Glass, J Clin Invest. 2004, 114, 1564.

[8] P. C. Calder, JPEN J Parenter Enteral Nutr. 2015, 39, $18 \mathrm{~S}$.

[9] B. Hennig, P. Meerarani, P. Ramadass, B. A. Watkins, M. Toborek, Metabolism. $2000,49,1006$. 
[10] M. Toborek, Y. W. Lee, S. Kaiser, B. Hennig, Methods Enzymol. 2002, 352, 198.

[11] H. Gremmels, L. M. Bevers, J. O. Fledderus, B. Braam, A. J. van Zonneveld, M. C. Verhaar, J. A. Joles, Eur J Pharmacol. 2015, 751:67-72., 10.1016/j.ejphar.2015.01.005. Epub 2015 Jan 13.

[12] C. O. de Souza, G. K. Vannice, J. C. Rosa Neto, P. C. Calder, Mol Nutr Food Res 2017, 5, 201700504.

[13] K. L. Chan, N. J. Pillon, D. M. Sivaloganathan, S. R. Costford, Z. Liu, M. Theret, B. Chazaud, A. Klip, J Biol Chem. 2015, 290, 16979.

[14] C. O. Souza, A. A. Teixeira, L. A. Biondo, L. S. Silveira, P. Calder, J. C. Rosa Neto, Clin Exp Pharmacol Physiol 2017, 30, 1440.

[15] H. L. Fisk, A. L. West, C. E. Childs, G. C. Burdge, P. C. Calder, J Vis Exp. 2014, (85). 10.3791/51445.

[16] C. J. Field, H. H. Blewett, S. Proctor, D. Vine, Appl Physiol Nutr Metab. 2009, $34,979$.

[17] L. Djousse, N. R. Matthan, A. H. Lichtenstein, J. M. Gaziano, Am J Cardiol. 2012, 110, 539.

[18] S. Dhall, D. S. Wijesinghe, Z. A. Karim, A. Castro, H. P. Vemana, F. T. Khasawneh, C. E. Chalfant, M. Martins-Green, Wound Repair Regen. 2015, 23, 644.

[19] J. P. Hardwick, K. Eckman, Y. K. Lee, M. A. Abdelmegeed, A. Esterle, W. M. Chilian, J. Y. Chiang, B. J. Song, Adv Pharmacol. 2013, 66:157-266., 10.1016/B978.

[20] H. Martynowicz, A. Janus, D. Nowacki, G. Mazur, Adv Clin Exp Med. 2014, 23, 319.

[21] M. Takeya, T. Yoshimura, E. J. Leonard, K. Takahashi, Hum Pathol. 1993, 24, 534.

[22] A. Sica, J. M. Wang, F. Colotta, E. Dejana, A. Mantovani, J. J. Oppenheim, C. G. Larsen, C. O. Zachariae, K. Matsushima, J Immunol. 1990, 144, 3034.

[23] M. J. Takkunen, V. D. de Mello, U. S. Schwab, J. J. Agren, J. Kuusisto, M. I. Uusitupa, Prostaglandins Leukot Essent Fatty Acids. 2014, 91, 169.

[24] H. J. Blewett, C. A. Gerdung, M. R. Ruth, S. D. Proctor, C. J. Field, Br J Nutr. 2009, 102, 526.

[25] M. Jacome-Sosa, C. Vacca, R. Mangat, A. Diane, R. C. Nelson, M. J. Reaney, J. Shen, J. M. Curtis, D. F. Vine, C. J. Field, M. Igarashi, D. Piomelli, S. Banni, S. D. Proctor, J Lipid Res. 2016, 57, 638.

[26] E. A. Lima, L. S. Silveira, L. N. Masi, A. R. Crisma, M. R. Davanso, G. I. Souza, A. B. Santamarina, R. G. Moreira, A. R. Martins, L. G. de Sousa, S. M. Hirabara, J. C. Rosa Neto, Mediators Inflamm. 2014, 2014:870634., 10.1155/2014/870634. Epub 2014 Sep 22.

[27] C. O. Souza, A. A. Teixeira, E. A. Lima, H. A. Batatinha, L. M. Gomes, M. Carvalho-Silva, I. T. Mota, E. L. Streck, S. M. Hirabara, J. C. Rosa Neto, Mediators Inflamm. 2014, 2014:582197., 10.1155/2014/582197. Epub 2014 Jul 24; X. Guo, H. Li, H. Xu, V. Halim, W. Zhang, H. Wang, K. T. Ong, S. L. Woo, R. L. Walzem, D. G. Mashek, H. Dong, F. Lu, L. Wei, Y. Huo, C. Wu, PLoS One. 2012, 7, e39286. doi: 10.1371/journal.pone.0039286. Epub 2012 Jun 29.

[28] W. Risau, Nature. 1997, 386, 671.

[29] Y. C. Lee, Curr Opin Investig Drugs. 2005, 6, 1124.

[30] S. Kliche, J. Waltenberger, IUBMB Life. 2001, 52, 61.

[31] A. Zernecke, C. Weber, Basic Res Cardiol. 2005, 100, 93.

[32] G. Brevetti, V. Schiano, M. Chiariello, Vasc Med. 2006, 11, 39.

[33] E. S. Collie-Duguid, K. W. Wahle, Biochem Biophys Res Commun. 1996, 220,

969; D. Zapolska-Downar, A. Siennicka, M. Kaczmarczyk, B. Kolodziej, M. Naruszewicz, J Nutr Biochem. 2004, 15, 220.

[34] R. Kostadinova, W. Wahli, L. Michalik, Curr Med Chem. 2005, 12, 2995.

[35] R. A. Daynes, D. C. Jones, Nat Rev Immunol. 2002, 2, 748. 
[36] Y. Rival, N. Beneteau, T. Taillandier, M. Pezet, E. Dupont-Passelaigue, J. F. Patoiseau, D. Junquero, F. C. Colpaert, A. Delhon, Eur J Pharmacol. 2002, 435, 143.

[37] A. Bolsoni-Lopes, W. T. Festuccia, T. S. Farias, P. Chimin, F. L. Torres-Leal, P. B. Derogis, P. B. de Andrade, S. Miyamoto, F. B. Lima, R. Curi, M. I. Alonso-Vale, Am J Physiol Endocrinol Metab. 2013, 305, E1093; C. O. Souza, A. A. Teixeira, L. A. Biondo, E. A. Lima, Jr., H. A. Batatinha, J. C. Rosa Neto, J Cell Physiol 2016, 7, 25715. [38] G. L. Pierce, L. A. Lesniewski, B. R. Lawson, S. D. Beske, D. R. Seals, Circulation. 2009, 119, 1284.

[39] M. Sarabi, B. Vessby, J. Millgard, L. Lind, Atherosclerosis. 2001, 156, 349.

[40] J. Merino, A. Sala-Vila, N. Plana, J. Girona, J. C. Vallve, D. Ibarretxe, E. Ros, R. Ferre, M. Heras, L. Masana, Nutr Metab Cardiovasc Dis. 2016, 26, 261.

[41] I. Cimen, B. Kocaturk, S. Koyuncu, O. Tufanli, U. I. Onat, A. D. Yildirim, O. Apaydin, S. Demirsoy, Z. G. Aykut, U. T. Nguyen, S. M. Watkins, G. S. Hotamisligil, E. Erbay, Sci Transl Med. 2016, 8, 358ra126. doi: 10.1126/scitransImed.aaf9087. 